\title{
Seroprevalence of Helicobacter pylori/CagA Antibodies in Guatemalan Gastric Cancer Patients: Association of Seropositivity with Increased Plasma Levels of Pepsinogens but not Soluble Urokinase Plasminogen Activator Receptor
}

\author{
Rafael Fernandez-Botran, ${ }^{1 *}$ Irmgardt Alicia Wellmann, ${ }^{2}$ Clas Une, ${ }^{3}$ Ericka Méndez-Chacón, ${ }^{3}$ Elisa Hernández de Rodas, ${ }^{2}$ \\ Bikash Bhandari, ${ }^{4}$ and Carmen I. Villagrán de Tercero ${ }^{2}$ \\ ${ }^{1}$ Department of Pathology \& Laboratory Medicine, University of Louisville, Louisville, Kentucky; ${ }^{2}$ Centro de Investigaciones Biomédicas, Facultad \\ de Ciencias Médicas, Universidad de San Carlos de Guatemala, Guatemala City, Guatemala; ${ }^{3}$ Instituto de Investigación en Salud (INISA), \\ Universidad de Costa Rica, San José, Costa Rica; ${ }^{4}$ Department of Bioinformatics and Biostatistics, School of Public Health and Information \\ Sciences, University of Louisville, Louisville, Kentucky
}

\begin{abstract}
Infection by Helicobacter pylori is a major risk factor for gastric cancer (GC), the second leading cause of cancer-related death worldwide. Although biomarkers such as pepsinogens (PGs) and soluble urokinase plasminogen activator receptor (suPAR) may have diagnostic and/or prognostic value in patients with GC, their levels may be affected by $H$. pylori infection. The aim of this study was to investigate the association of the presence of antibodies to $H$. pylori and cytotoxin-associated gene A (CagA) with plasma levels of PGs and suPAR in a cohort of Guatemalan GC patients and controls. To this end, levels of suPAR, Pepsinogens I and II (PGI and PGII), and antibodies to H. pylori and CagA toxin were determined by ELISA in plasma samples from $67 \mathrm{GC}$ patients and 136 matched healthy controls. Seropositivity for CagA was significantly higher in patients with GC than in controls. Pepsinogens II and suPAR levels were higher and PGI/PGII ratios were lower in GC patients than in controls. There was a significant association of $H$. pylori seropositivity status with increased levels of PGIl and lower PGI/PGIl ratios, particularly in the control (non-GC) population. The levels of suPAR were not significantly affected by $\mathrm{H}$. pylori or $\mathrm{CagA}$ seropositivity status. These results suggest that the seropositivity status for $H$. pylori and CagA need to be taken into account during the GC diagnostic process.
\end{abstract}

\section{INTRODUCTION}

Gastric cancer (GC) is the most common neoplasia of the gastrointestinal (Gl) tract and the fifth most common type of cancer in the world, with a frequency that varies greatly depending on the geographic location, with some of the highest risk areas located in Asia, particularly Japan, Korea, and China, as well as in some Latin American countries. ${ }^{1-3}$ In Guatemala, GC presents some of the highest rates of incidence and mortality in the world and occupies the fourth place among the most common cancers for both genders. ${ }^{2,4}$ The risk of GC is slightly higher for males and affected by a number of other factors, including genetics, weight, diet, and socioeconomic level. ${ }^{5,6}$ However, the most significant risk factor appears to be infection by Helicobacter pylori, a Gramnegative bacteria adapted to the stomach microenvironment that has the ability to invade the gastric mucosa and cause inflammation, leading to gastritis, ulcers, and neoplasia. ${ }^{5,7} \mathrm{Al}-$ though $85 \%$ of people infected do not develop symptoms, those who do are often infected by pathogenic strains of $H$. pylori. Such strains carry a pathogenicity island in their genomes encoding cytotoxin-associated gene $\mathrm{A}$ (CagA), a major virulence factor whose presence has been directly associated with ulcer-causing $H$. pylori strains. ${ }^{8-10}$ Helicobacter pylori strains producing CagA are more likely to cause tissue damage and inflammation than those that lack their production, and thus more likely to be associated with GC. ${ }^{11,12}$

There has been a lot of interest in the identification of diagnostic and prognostic biomarkers for GC. Among some of the markers receiving the most attention are the plasma levels of pepsinogens (PGs). Pepsinogens I and II (PGI and PGII) are two biochemically and immunologically distinct proenzymes

* Address correspondence to Rafael Fernandez-Botran, Department of Pathology \& Laboratory Medicine, University of Louisville, 511 South Floyd St., Louisville, KY 40292. E-mail: rafael@louisville.edu of pepsin with different patterns of expression in the stomach. Whereas PGI is mainly expressed by chief cells in the fundus, PGII is distributed throughout the gastric mucosa and the proximal duodenum. ${ }^{13,14}$ The levels of PGI and PGI/PGIl ratios in serum correlate with morphological and functional changes in the gastric mucosa and have been proposed as markers of atrophic gastritis and GC. ${ }^{15-20}$ However, although relatively useful, PG tests may have limitations that affect their sensitivity and specificity for the detection of GC. In addition to several demographic and pathologic factors, PG tests have been reported to be affected by $H$. pylori infection. ${ }^{5-7,21}$

Another potentially important biomarker associated with a number of malignancies, including $\mathrm{GC}$, is the urokinase plasminogen activator receptor (UPAR or CD87). ${ }^{22-24}$ As a regulator of fibrinolysis through the binding and activation of urokinase plasminogen activator, UPAR is associated with degradation of the extracellular matrix and basement membranes, important factors in tumor cell invasion, and metastasis. ${ }^{23-26}$ Soluble urokinase plasminogen activator receptor (suPAR) may be generated by several mechanisms, including cleavage of the GPI anchor by phospholipases, cleavage by proteolytic enzymes, and alternative mRNA splicing. ${ }^{27-30}$ Both membrane and soluble forms of uPAR have been reported in neoplastic cell lines and in several types of in vivo malignancies, including gastric, colon, breast, and lung cancers. ${ }^{22,31,32}$ Increased UPAR expression in tumor tissue has been correlated with a poor prognosis, and elevated levels of suPAR have been reported in the sera of patients with GC as well as other cancers, suggesting a potential use as a diagnostic/prognostic biomarker. ${ }^{31,33-37}$ Although $H$. pylori infection has been reported to promote UPAR expression in gastric epithelial and gastric carcinoma cells, ${ }^{10,38}$ the effect on the plasma levels of suPAR levels has not been studied.

The purpose of this study was to determine the seroprevalence of $H$. pylori and CagA antibodies in a cohort of Guatemalan GC patients and controls and to investigate 
whether the seropositivity status affects the plasma levels of PGs and suPAR.

\section{MATERIALS AND METHODS}

Study design and subjects. Sixty-seven patients who were diagnosed with gastric adenocarcinoma and 136 age- and gender-matched healthy controls were included in the study. Most patients and controls self-identified as "Ladino" or "indigenous," the two main ethno-cultural groups recognized in Guatemala (the Guatemalan population is roughly $60 \%$ Ladino or mestizo and $40 \%$ indigenous or Mayan, with a low percentage of other groups). Subjects were recruited after understanding and signing written consent from the Institute of Cancerology (Instituto de Cancerología-INCAN), the Roosevelt Hospital, the Center for Biomedical Research (Centro de Investigaciones Biomédicas) of the Universidad San Carlos de Guatemala, and the Gastro-Centro, all in Guatemala City, Guatemala, between February and September 2015. The study was reviewed and approved by the Institutional Review Boards from the aforementioned institutions and conformed with the Code of Ethics of the World Medical Association (Declaration of Helsinki), printed in the British Medical Journal (July 18, 1964).

Inclusion criteria. Cancer group. The group included patients aged 18 years or older with a diagnosis of distal or proximal gastric adenocarcinoma based on endoscopy and histopathologic analysis of a gastric biopsy.

Control group. The group included healthy subjects aged 18 years or older willing to participate in the study. Subjects were recruited from asymptomatic and non-oncologic patients attending ambulatory care gastroenterology clinics at the Institute of Cancerology and the Roosevelt Hospital or from persons undergoing routine laboratory tests at the Center for Biomedical Research of the Universidad San Carlos de Guatemala.

Exclusion criteria. Cancer group. The group included patients previously operated for GC or with metastatic tumors originating in other organs and treated for mucosa-associated lymphoid tissue (MALT) lymphoma or any other gastric disease besides gastric adenocarcinoma. Patients previously treated with chemotherapy and/or radiotherapy and/or diagnosed with autoimmune pathologies were also included.

Control group. The group included subjects with a history of malignancy of any type, treated for gastric disease and/or previously diagnosed with autoimmune pathologies.

Diagnosis. The diagnosis of the gastric adenocarcinoma cases was based on an upper GI endoscopy procedure and histopathologic analysis of a gastric biopsy. Data were collected for each cancer case on the macroscopic (Borrmann classification $^{39}$ ) and microscopic/histologic features of the tumors (Lauren classification ${ }^{40}$ ), the number of affected sites, and localization in the stomach.

Samples. Fasting venous blood samples from controls and cancer patients were obtained using $\mathrm{K}_{2}$ EDTA vacutainer tubes before GC treatment. Samples were maintained at $4^{\circ} \mathrm{C}$ and processed within 1 hour of collection. The tubes were centrifuged at $500 \times g$ for 10 minutes, and the plasma was removed by aspiration and aliquoted. Plasma samples were then stored at $-70^{\circ} \mathrm{C}$, until assayed.

Helicobacter pylori serology. Serum antibodies to H. pylori were measured using a qualitative ELISA based on a modification of a previously described method. ${ }^{41}$ Briefly, antigen was prepared by sonicating five different strains of $H$. pylori isolated from patients in Costa Rica. ELISA plates (Immulon 2HB, Thermo Scientific, Waltham, MA) were coated with $100 \mu \mathrm{L}$ of the antigen preparation $(100 \mathrm{ng} / \mathrm{mL}$ in carbonate buffer, $\mathrm{pH} 9.6)$ by overnight incubation at room temperature followed by blocking with $250 \mu \mathrm{L}$ of $0.1 \%$ gelatin in phosphate-buffered saline (PBS) for 3 hours. Serum samples and negative internal controls (diluted $1: 800$ in PBS containing $0.1 \%$ gelatin and $0.5 \%$ bovine gamma globulin [Sigma, St. Louis, MO]) were added to the wells and incubated at $37^{\circ} \mathrm{C}$ for 60 minutes. Positive internal controls were also included but diluted 1:7,500. After washing, the wells were incubated for 1 hour at $37^{\circ} \mathrm{C}$ with a goat anti-antihuman IgG antibody conjugated with alkaline phosphatase (Biosource International). Detection was performed by the addition of substrate (Fast p-Nitrophenyl Phosphate Tablet Sets, Sigma-Aldrich, St. Louis, MO) and reading at $405 \mathrm{~nm}$. A sample was considered positive when the net absorbance of the serum was higher or equal to 0.75 of the average positive control. Each sample was assayed three times, and sera were considered positive when at least two of the three tests resulted positive. Validation of the ELISA was previously performed using 230 sera from persons with known $H$. pylori status as determined by the urea breath test (Ballard Medical Products, Draper, UT). The positive and negative predictive values were $96 \%$ and $90 \%$, respectively.

Cytotoxin-associated gene A serology. Serum antibodies to CagA were measured using a modified version of the ELISA described by Blaser et al. ${ }^{42}$ Briefly, ELISA plates coated with purified recombinant CagA antigen were incubated with serum samples and controls, all diluted (1:100). The subsequent steps were identical to those performed for the $H$. Pylori serology described in the previous section. The CagA ELISA has been validated comparing serum samples from subjects confirmed to be infected or not infected with CagA-positive strains of $H$. pylori. The optimal cutoff point was at 0.3 of the average positive control.

Soluble urokinase plasminogen activator receptor and pepsinogen assays. Levels of suPAR in plasma were quantified using commercial ELISA kits (Human UPAR Immunoassay, R\&D Systems, Minneapolis, MN) according to the manufacturer's instructions.

Levels of pepsinogens I and II (PGI and PGII) in plasma were assayed using ELISA methodology (Biohit Oyj, Finland). The PGI/PGIl ratio was calculated by dividing the corresponding concentrations of the two PGs.

Statistics. Sample size was established following a power analysis using the EPIDAT program and a moderate effect size $(d=0.5)$ based on previously published data on suPAR levels, a sample ratio of 2.0 , a confidence level of $95 \%$, and a power of $90 \%$. Initially, the Shapiro-Wilk test was used to determine whether the data were normally distributed. The Chi-square test was used to analyze differences in the positivity rate for the serological markers and effects of ethnicity. Because of non-normal distribution, the Wilcoxon-Mann-Whitney test was used to compare the levels of suPAR, PGs, and PGI/PGII ratios between the two groups and to compare data for the two microscopic tumor types. Point biserial correlation analysis was used to analyze the correlation between the biomarkers and positivity for $H$. pylori and CagA antibodies. Statistical analyses were performed using SAS ${ }^{\circledR} 9.4$ (SAS Institute, Cary, NC). $P$-values of $<0.05$ were considered statistically significant. 
TABLE 1

Subject groups-demographical and serological characteristics

\begin{tabular}{lccc}
\hline \multicolumn{1}{c}{ Variable } & $\begin{array}{c}\text { Control group } \\
(\mathrm{n}=136)\end{array}$ & $\begin{array}{c}\text { Cancer group } \\
(n=67)\end{array}$ & $P$-value \\
\hline Gender & & & \\
$\quad$ Female & $60(44.1 \%)$ & $30(44.8 \%)$ & \\
$\quad$ Male & $76(55.9 \%)$ & $37(55.2 \%)$ & \\
$\quad$ Age (years), mean \pm SD & $58.5 \pm 12.6$ & $59.5 \pm 13.0$ & 0.630 \\
Ethnicity & & & \\
$\quad$ Ladino & $118(86.8 \%)$ & $48(71.6 \%)$ & \\
$\quad$ Indigenous & $17(12.5 \%)$ & $18(26.9 \%)$ & \\
$\quad$ Other & $1(0.7 \%)$ & $1(1.5 \%)$ & \\
Serology & & & \\
$\quad$ H. pylori (positive) & $64(45.5 \%)$ & $34(50.8 \%)$ & 0.522 \\
$\quad$ CagA (positive) & $75(53.2 \%)$ & $49(73.1 \%)$ & $0.007^{\star}$ \\
\hline $\begin{array}{l}\text { H. pylori = Helicobacter pylori. } \\
{ }^{*} P<0.001 .\end{array}$ & & &
\end{tabular}

\section{RESULTS}

Demographic data. Table 1 shows the demographic and serologic characteristics of the cancer and control groups. Both of them were composed of approximately $44 \%$ females and $56 \%$ males, respectively. The average age of the cancer group (59.5 years) was not significantly different from that of the control group (58.5 years; $P=0.630$ ). Breakdown by ethno-cultural groups indicated a composition of $70.6 \%$ Ladino, $27.9 \%$ indigenous, and $1.5 \%$ other for the cancer group, and $86.8 \%$ Ladino, $12.5 \%$ indigenous, and $0.7 \%$ other for the control group. The seropositivity rates for $\mathrm{H}$. pylori between the control and cancer groups (45.5 versus $50.8 \%$, respectively; $P=0.522$ ) were not significantly different. However, the prevalence of anti-CagA antibodies was found to be significantly higher in patients with GC than in controls (73.1 versus $53.2 \%$, respectively; $P=0.007$; odds ratio $=2.396$ ).

Gastric cancer case characteristics. Table 2 summarizes the characteristics of the GC cases. Macroscopically, the most common presentation was type III (ulcerative with indistinct borders) of the Borrmann classification (72\%), followed by types I (polypoid fungating) and IV (diffuse, indistinct borders) with $12 \%$ and $11 \%$ of the cases, respectively. Microscopically, most of the tumors were diagnosed as either intestinal (55\%) or diffuse (42\%), with the remaining $3 \%$ being mixed, according to the Lauren classification. In terms of localization in the stomach, the body and the antrum were the most common sites $(46 \%$ and $37 \%$, respectively), followed by the fundus (15\%) and pylorus $(3 \%)$. The GC group comprised patients at all clinical stages, including stages I (7.5\%), II (40.3\%), III (22.4\%), and IV (28.4\%).

Ethnicity and differences in microbiological markers and microscopic tumor types. Comparisons of the prevalence of antibodies to $H$. pylori and CagA as well as that of the two main microscopic tumor types between the two main Guatemalan ethnic groups are shown in Table 3. There were no statistically significant differences in the seropositivity rates for $H$. pylori between the Ladino and indigenous populations, and although the latter population showed a moderately higher seropositivity rate for $\mathrm{CagA}$, the difference with the Ladino population (71.4 versus $57.2 \%$, respectively) was not statistically significant. Although the distributions of intestinal versus diffuse GC types in the Ladino and indigenous groups were almost reversed, with the intestinal type being more prevalent in the former and the diffuse type in the latter
TABLE 2

Gastric cancer case characteristics

\begin{tabular}{lc}
\hline \multicolumn{1}{c}{ Variable } & $\begin{array}{c}\text { Number }(\%) \\
(n=67)\end{array}$ \\
\hline Tumor type (macroscopic-Borrmann classification $\sim)$ & \\
Type I (polypoid and fungating) & $8(11.9)$ \\
Type II (ulcerative with elevated distinct borders) & $4(6.0)$ \\
Type III (ulcerative with indistinct borders) & $48(71.6)$ \\
Type IV (diffuse and indistinct borders) & $7(10.5)$ \\
Tumor type (microscopic_Lauren classification) & \\
Intestinal & $37(55.2)$ \\
Diffuse & $28(41.8)$ \\
Mixed & $2(3.0)$ \\
Anatomical localization* & \\
Cardia & $0(0)$ \\
Fundus & $10(14.9)$ \\
Body & $30(44.8)$ \\
Antrum & $25(37.3)$ \\
Pylorus & $2(3.0)$ \\
Clinical stage & \\
I & $5(7.5)$ \\
II & $27(40.3)$ \\
III & $15(22.4)$ \\
IV & $19(28.4)$ \\
Undetermined & $1(1.5)$ \\
\hline *For those cases with two or more sites, the primary localization was considered.
\end{tabular}

group (about two-thirds in each case), the differences were not statistically significant. There were no statistically significant differences in the seropositivity for $H$. pylori or CagA antibodies when comparing individuals with intestinal versus diffuse tumors (results not shown).

Biochemical markers: Levels of PGs and suPAR in cancer and control groups. Results of the determinations of plasma PGI, PGIl, and PGI/PGIl ratios and suPAR levels in the cancer and control groups are shown in Table 4. Analysis of pepsinogen levels indicated that although there was no statistically significant difference in the levels of PGI between the two groups, the levels of PGIl were significantly higher in the cancer than in the control group. There was also a significant difference between the two groups in PGI/ PGIl ratios: these being lower in the cancer group. The cancer group had significantly higher levels of suPAR than the controls $(P<0.0001)$.

Correlation between serological and biochemical markers. Table 5 shows the association between seropositivity for anti-H. pylori or CagA antibodies with the levels of the biochemical markers. Because of the potential confounding effect of the presence of GC, these studies analyzed data from the control and cancer groups separately. The comparison of median biomarker levels of $H$. pylori-seronegative versus seropositive individuals in the control group suggested that the levels of both PGs, but particularly PGIl, were higher in the seropositive individuals, whereas PGI/PGIl ratios were lower. These effects were not as evident in the cancer group, with exception of smaller effect on PGIl levels. A point biserial correlation analysis showed a moderate positive correlation between seropositivity for $H$. pylori and the levels of PGIl and a negative correlation with the PGI/PGIl ratios in the control group. The comparison of CagA-seronegative versus seropositive individuals showed significantly higher levels of PGII in seropositive individuals in both the control and cancer groups as well as lower PGI/PGll ratios in the latter. The plasma levels of suPAR were not affected by $H$. pylori or CagA status in either group. 
TABLE 3

Distribution by ethnicity

\begin{tabular}{lrrr}
\hline \multicolumn{1}{c}{ Variable } & \multicolumn{1}{c}{ Ladino, $n(\%)$} & Indigenous, $n(\%)$ & $P$-value \\
\hline Serology* & & & \\
H. pylori (positive) & $80(48.2)$ & $19(54.3)$ & 0.512 \\
CagA (positive) & $95(57.2)$ & $25(71.4)$ & 0.120 \\
Tumor type (Lauren classification) $\dagger$ & & \\
Intestinal & $31(64.6)$ & $7(38.9)$ & \\
Diffuse & $17(35.4)$ & $11(61.1)$ & 0.060 \\
\hline
\end{tabular}

H. pylori $=$ Helicobacter pylori.

Serology (Ladino, $n=166$; indigenous, $n=35$ )

† Tumor type (Ladino, $n=48$; indigenous, $n=18$ ).

\section{DISCUSSION}

The main objective of this study was to evaluate the association of seropositivity status for antibodies to $H$. pylori and CagA with the levels of PGI, PGIl, and their ratios (biochemical markers associated with the presence of atrophy and GC) as well as those of suPAR in a cohort of Guatemalan GC patients and controls. Serologic analysis indicated that there were no statistically significant differences in the seropositivity for $H$. pylori in GC patients and controls, accounting for approximately half of the population in each group, a seropositivity rate that is in line with previous studies in the Guatemalan population. ${ }^{43,44}$ However, seropositivity for anti-CagA antibodies was significantly higher in patients with $\mathrm{GC}(P=0.007)$, confirming that infection with pathogenic strains of $H$. pylori is an important risk factor for GC. The finding of individuals from both groups who were positive for CagA but negative for $H$. pylori antibodies $[H$. pylori $(-) / \mathrm{CagA}(+)]$ was not totally unexpected, as this has been previously reported by other studies and attributed to insufficiently high levels of antibodies to the $H$. pylori antigens used in the ELISA. ${ }^{11}$ We also found $H$. pylori (+)/CagA (-) individuals in both the GC (4.4\%) and control groups (10.3\%). These individuals might represent infections with $H$. pylori CagA strains. We also compared the H. pylori (+)/CagA (-) individuals with H. pylori (-)/CagA (+) and $H$. pylori $(+) / \mathrm{CagA}(+)$ individuals in terms of their biomarkers (PGI, PGIl, and PGI/PGIl ratios and suPAR levels), but found no statistically significant differences. However, $H$. pylori $(+) / \mathrm{CagA}(+)$ individuals in the control group had significantly higher median levels of PGIl (18.4 versus $8.4 \mathrm{ng} / \mathrm{mL} ; P<0.001$ ) and lower PGI/PGII ratios (7.8 versus $12.8 ; P<0.001)$ than those that were $H$. pylori $(-) / C a g A(+)$, suggesting that individuals who are seropositive for both $H$. pylori and CagA are more likely to have higher levels of PGIl and lower PGI/PGII ratios than those positive for CagA only. One plausible interpretation is that seroconversion for CagA antibodies might be more sensitive and require a smaller bacterial exposure than seroconversion for $H$. pylori antibodies, as measured by the current ELISA tests. The latter may require a more substantial exposure or infection with the bacteria and, thus, might better correlate clinically with gastric mucosal inflammation and the observed elevated levels of PGIl and lower PGI/PGIl ratios.

Investigation of whether GC cases in Guatemala differ among ethno-cultural divisions showed no statistically significant differences. However, we observed that the patterns of distribution of the two main microscopic GC types (intestinal versus diffuse) were almost opposite in the Ladino versus indigenous population, with the intestinal type accounting for almost two-thirds of the GC cases in the
TABLE 4

Biomarker levels

\begin{tabular}{lccc}
\hline \multicolumn{1}{c}{ Variable } & Control group $(n=136)$ & Cancer group $(n=67)$ & $P$-value \\
\hline PGI $(\mathrm{ng} / \mathrm{mL})$ & $149.0(95.9)$ & $124.2(150.3)$ & 0.455 \\
PGII $(\mathrm{ng} / \mathrm{mL})$ & $12.6(11.4)$ & $20.4(16.3)$ & $0.003^{*}$ \\
PGI/PGII ratio & $10.9(7.9)$ & $7.4(5.3)$ & $<0.0001^{*}$ \\
suPAR $(\mathrm{ng} / \mathrm{mL})$ & $2.01(0.85)$ & $3.15(2.73)$ & $<0.0001^{*}$ \\
\hline
\end{tabular}

Pepsinogens I = PGl; Pepsinogens II = PGIl; suPAR = soluble urokinase plasminogen activator receptor. Values represent median (IQR).

${ }^{\star} P<0.01$.

former and the diffuse type for two-thirds in the latter population. Although not statistically significant, these results are provocative and call for a more extensive investigation.

Our studies found that PGI/PGIl ratios were significantly lower in patients with GC than in controls. The lower PGI/PGIl ratios in our study appeared to be a consequence of higher levels of PGIl in the cancer group than in the controls because the levels of PGI were not significantly different between the two groups. Increased PGIl levels and lower PGI/PGIl ratios have been reported to be major risk factors for gastric ulcers by Samloff and others. ${ }^{45}$ Elevated serum PGIl levels have also been associated with infiltration of the gastric mucosa by neutrophils and monocytes as a result of $H$. pylori infection. ${ }^{46}$ Indeed, our studies found that even individuals without GC who were seropositive for $H$. pylori or CagA antibodies had higher levels of plasma PGIl (as well as lower PGI/PGIl ratios) than seronegative individuals. Such findings suggest the importance of taking into account the serological status for $H$. pylori when evaluating PG levels in patients at risk of GC.

Our group recently reported the presence of higher levels of plasma suPAR in a cohort of Guatemalan patients with $\mathrm{GC},{ }^{47}$ consistent with previous studies reporting elevated suPAR levels in patients GC and other types of cancer. ${ }^{22,24,35-37} \mathrm{Al}-$ though some of these studies have also reported a prognostic value for suPAR tests, with higher levels being associated with reduced survival, ${ }^{31,35-37}$ the mechanisms underlying the increased suPAR levels in patients with cancer are not yet clear. High levels of uPAR expression have not only been demonstrated in malignant cells but also in stromal cells, such as macrophages, neutrophils, and endothelial cells. ${ }^{48,49}$ Thus, elevated suPAR levels could probably reflect both enhanced tissue remodeling and inflammation. ${ }^{24,31}$ Taking into account that suPAR levels are not specific for any particular type of cancer, these characteristics would be consistent with suPAR levels being a better prognostic rather than diagnostic marker. From the point of view of pathogenic mechanisms and based on the biological roles of UPAR, including plasmin activation and matrix degradation as well as activation of signaling pathways leading to alterations in cell adhesion and motility, high UPAR expression in the tumor microenvironment may endow malignant cells with a clear advantage in terms of tissue invasion, angiogenesis, and metastasis. ${ }^{21,25,30}$ Despite reports that $H$. pylori infection of gastric epithelial and gastric carcinoma cells promoted UPAR expression in these cells, ${ }^{9,38}$ our studies found that plasma suPAR levels were not affected by seropositivity rates for $H$. pylori or CagA, suggesting that the use of suPAR levels as a potential GC marker may not be complicated by previous $H$. pylori infection.

This study has several limitations. Our control population included only age- and gender-matched, healthy individuals. 
TABLE 5

Association of $H$. pylori and CagA seropositivity with biochemical markers

\begin{tabular}{|c|c|c|c|c|}
\hline Biochemical marker & H. pylori negative & H. pylori positive & $P$-value & $\begin{array}{l}\text { Point biserial correlation } \\
\text { rbp ( } P \text {-value) }\end{array}$ \\
\hline \multicolumn{5}{|l|}{ Control group } \\
\hline PGI (ng/mL) & $112.9(99.2)$ & $164.5(68.8)$ & $0.001^{\star \star}$ & $0.237(0.006)^{\star}$ \\
\hline PGII (ng/mL) & $8.2(6.6)$ & $17.8(11.0)$ & $<0.0001^{\star *}$ & $0.383(<0.0001)^{\star \star}$ \\
\hline PGI/PGIl ratio & $13.1(8.5)$ & $8.4(6.1)$ & $<0.0001^{\star *}$ & $-0.337(<0.0001)^{\star \star}$ \\
\hline suPAR $(\mathrm{ng} / \mathrm{mL})$ & $1.92(1.04)$ & $2.01(0.69)$ & 0.517 & $-0.103(0.235)$ \\
\hline \multicolumn{5}{|l|}{ Cancer group } \\
\hline PGI (U/mL) & $117.6(170.1)$ & $118.3(128.5)$ & 0.430 & $0.028(0.823)$ \\
\hline PGII (U/mL) & $14.5(17.7)$ & $22.3(15.5)$ & $0.044^{*}$ & $0.099(0.433)$ \\
\hline PGI/PGII ratio & $9.3(8.4)$ & $6.4(4.7)$ & 0.069 & $-0.250(0.045)^{\star}$ \\
\hline suPAR (ng/mL) & 3.66 (2.49) & 2.51 (3.01) & 0.099 & $-0.083(0.516)$ \\
\hline & CagA neg. & CagA pos. & & \\
\hline \multicolumn{5}{|l|}{ Control group } \\
\hline PGI (U/mL) & 136.7 (95.9) & $154.9(94.2)$ & 0.080 & $0.124(0.152)$ \\
\hline PGII (U/mL) & $9.0(9.7)$ & $15.3(10.8)$ & $0.001^{\star \star}$ & $0.148(0.086)$ \\
\hline PGI/PGIl ratio & $12.3(8.2)$ & $9.8(6.2)$ & 0.063 & $-0.152(0.077)$ \\
\hline suPAR $(\mathrm{ng} / \mathrm{mL})$ & $1.92(0.90)$ & $2.02(0.82)$ & 0.418 & $0.063(0.467)$ \\
\hline \multicolumn{5}{|l|}{ Cancer group } \\
\hline PGI (U/mL) & $124.2(188.8)$ & $118.3(136.5)$ & 0.532 & $0.101(0.421)$ \\
\hline PGII (U/mL) & $11.6(16.7)$ & $21.8(17.1)$ & $0.036^{\star}$ & $0.244(0.048)^{*}$ \\
\hline PGI/PGIl ratio & $11.1(9.7)$ & $6.4(4.9)$ & $0.030^{*}$ & $-0.291(0.018)^{\star}$ \\
\hline suPAR (ng/mL) & $3.86(4.12)$ & $2.91(2.58)$ & 0.403 & $-0.095(0.450)$ \\
\hline
\end{tabular}

Because suPAR levels may also be elevated in other cancers and even in cases when there is systemic inflammation, they alone should not be taken as specific for GC. It is also not clear how premalignant gastric pathologies (e.g., atrophic gastritis) may affect suPAR levels, and thus, additional studies need to be undertaken to evaluate patients with such conditions.

In conclusion, our studies demonstrated that in the Guatemalan population studied, the presence of GC was significantly associated with seropositivity for CagA antibodies. The levels of PGII and suPAR were found to be higher and PGI/PGIl ratios lower in GC patients than in controls. However, a significant association was found between $\mathrm{H}$. pylori seropositivity and increased levels of PGII and lower PGI/PGIl ratios, even in the control (non-GC) population. By contrast, the levels of suPAR were not affected. These results suggest that the seropositivity status for $H$. pylori and CagA need to be taken into account during the GC diagnosis workup.

Received December 16, 2019. Accepted for publication March 8, 2020.

Published online April 20, 2020.

Financial support: This study was supported by a Research Initiation Grant from the University of Louisville (R. F .B.); grant 4.8.63.1.77 from the Dirección General de Investigación (DIGI), Universidad de San Carlos de Guatemala (I. A .W.); and a network grant 742-B3-766 from the Universidad de Costa Rica (C. U. and E. M. C.).

Authors' addresses: Rafael Fernandez-Botran, Department of Pathology \& Laboratory Medicine, University of Louisville, Louisville, KY, E-mail: rafael@louisville.edu. Irmgardt Alicia Wellmann, Elisa Hernández de Rodas, and Carmen I. Villagrán de Tercero, Centro de Investigaciones Biomédicas, Facultad de Ciencias Médicas, Universidad de San Carlos de Guatemala, Guatemala City, Guatemala, E-mails: irmgardtina@ gmail.com, elisaherlo@gmail.com, and carmendetercero@gmail.com. Clas Une and Ericka Méndez-Chacón, Instituto de Investigación en Salud (INISA), Universidad de Costa Rica, San José, Costa Rica, E-mails: allan.une@ucr.ac.cr and erickamc2002@gmail.com. Bikash Bhandari,
Department of Bioinformatics and Biostatistics, School of Public Health and Information Sciences, University of Louisville, Louisville, KY, E-mail: bikashten@gmail.com.

\section{REFERENCES}

1. Ferlay J, Ervik M, Lam F, Colombet M, Mery L, Piñeros M, Naor A, Soerjomataram I, Bray F, 2018. Global Cancer Observatory: Cancer Today. Lyon, France: International Agency for Research on Cancer. Available at: https://gco.iarc.fr/today.

2. Ferlay J, Colombet M, Soerjomataram I, Mathers C, Parkin DM, Piñeros M, Znaor A, Bray F, 2019. Estimating the global cancer incidence and mortality in 2018: GLOBOCAN sources and methods. Int J Cancer 144: 1941-1953.

3. Ferro A, Peleteiro B, Malvezzi M, Bosetti C, Bertuccio P, Levi F, Negri E, La Vecchia C, Lunet N, 2014. Worldwide trends in gastric cancer mortality (1980-2011), with predictions to 2015, and incidence by subtype. Eur J Cancer 50: 1330-1344.

4. Nagini S, 2012. Carcinoma of the stomach: a review of epidemiology, pathogenesis, molecular genetics and chemoprevention. World J Gastrointest Oncol 4: 156-169.

5. Carcas LP, 2014. Gastric cancer review. J Carcinog 13: 14.

6. Dicken BJ, Bigam DL, Cass C, Mackey JR, Joy AA, Hamilton SM, 2005. Gastric adenocarcinoma. Review and considerations for future directions. Ann Surg 241: 27-39.

7. Blasser MJ, 2006. Who are we? Indigenous microbes and the ecology of human diseases. EMBO Rep 7: 956-960.

8. Smoot DT, 1997. How does Helicobacter pylori cause mucosal damage? Direct mechanisms. Gastroenterology 113 (Suppl 6): S31-S34.

9. Shiotani AD, Graham Y, 2002. Pathogenesis and therapy of gastric and duodenal ulcer disease. Med Clin North Am 86: 1447-1466.

10. Kim MH, Yoo HS, Kim MY, Jang HJ, Baek MK, Kim HR, Shin BA, Ahn BW, Jung YD, 2007. Helicobacter pylori stimulates urokinase plasminogen activator receptor expression and cell invasiveness through reactive oxygen species and NF-KB signaling in human gastric carcinoma cells. Intl J Mol Med 19: 689-697.

11. Nomura AMY, Lee J, Stemmerman GN, Nomura RY, Perez-Perez G, Blaser MJ, 2002. Helicobacterpylori CagA seropositivity and risk of gastric cancer in a Japanese American population. $J$ Infect Dis 186: 1138-1144. 
12. Maeda S et al., 2002. Assessment of gastric carcinoma risk associated with Helicobacter pylori may vary depending on the antigen used: CagA specific enzyme-linked immunoadsorbent assay (ELISA) versus commercially available $H$. pylori ELISAs. Cancer 88: 1530-1535.

13. Samloff IM, 1971. Cellular localization of group I pepsinogens in human gastric mucosa by immunofluorescence. Gastroenterology 61: 185-188.

14. Samloff IM, Liebman WM, 1973. Cellular localization of group II pepsinogens in human stomach and duodenum. Gastroenterology 65: 36-42.

15. Broutet N, Plebani M, Sakarovitch C, Sipponen P, Mégraud F; Eurohepygast Study Group, 2003. Pepsinogen A, pepsinogen $\mathrm{C}$, and gastrin as markers of atrophic chronic gastritis in European dyspeptics. Br J Cancer 88: 1239-1247.

16. Dinis-Ribeiro M, da Costa-Pereira A, Lopes C, Barbosa J, Guilherme M, Moreira-Dias L, Lomba-Viana H, Silva R, Abreu N, Lomba-Viana R, 2004. Validity of serum pepsinogen I/II ratio for the diagnosis of gastric epithelial dysplasia and intestinal metaplasia during the follow-up of patients at risk for intestinaltype gastric adenocarcinoma. Neoplasia 6: 449-456.

17. Li P, He C, Sun L, Dong N, Yuan Y, 2013. Pepsinogen I and II expressions in situ and their correlations with serum pepsinogen levels in gastric cancer and its precancerous disease. BMC Clin Path 13: 22

18. Oishi $Y$ et al., 2006. The serum pepsinogen test as a predictor of gastric cancer: The Hisayama study. Am J Epidemiol 163: 629-637.

19. Sierra R, Mena F, Ramírez V, Mendez E, Salazar M, Une C, 2003. Pepsinógenos séricos para detectar cáncer gástrico en Costa Rica. Acta Bioquím Clín Latinoam 37: 357-362.

20. Sierra $R$ et al., 2006. Association of serum pepsinogen with atrophic body gastritis in Costa Rica. Clin Exp Med 6: 72-78.

21. Kim N, Jung HC, 2010. The role of serum pepsinogen in the detection of gastric cancer. Gut Liver 4: 307-319.

22. Dass K, Ahmad A, Azmi AS, Sarkar SH, Sarkar FH, 2002. Evolving role of the uPA/uPAR system in human cancers. Cancer Treat Rev 34: 122-136.

23. Eugen-Olsen J, Giamarellos-Borboulis EJ, 2015. suPAR: the unspecific marker for disease presence, severity and prognosis. Intl J Antimicrob Ag 46: S33-S34.

24. Mahmood N, Mihalciolu C, Rabbani SA, 2018. Multifaceted role of the urokinase-type plasminogen activator (UPA) and its receptor (UPAR): diagnostic, prognostic, and therapeutic applications. Front Oncol 8: 24.

25. Danø K, Behrendt N, Brünner N, Ellis V, Ploug M, Pyke C, 1994. The urokinase receptor. Protein structure and role in plasminogen activation and cancer invasion. Fibrinolysis 8 (Supp/ 1): 189-203.

26. Mondino A, Blasi F, 2004. uPA and uPAR in fibrinolysis, immunity and pathology. Trends Immunol 25: 450-455

27. Høyer-Hansen G, Behrendt N, Ploug M, Danø K, Preissner KT, 1997. The intact urokinase receptor is required for efficient vitronectin binding: receptor cleavage prevents ligand interaction. FEBS Lett 420: 79-85.

28. Høyer-Hansen G, Ploug M, Behrendt N, Rønne E, Danø K, 1997. Cell-surface acceleration of urokinase-catalyzed receptor cleavage. J Biochem 243: 21-26.

29. Sidenius N, Sier CFM, Blasi F, 2000. Shedding and cleavage of the urokinase receptor (UPAR): identification and characterisation of UPAR fragments in vitro and in vivo. FEBS Lett 475: 52-56.

30. Stewart CE, Sayers I, 2009. Characterisation of urokinase plasminogen activator receptor variants in human airway and peripheral cells. BMC Mol Biol 10: 75

31. Boonstra MC, Verspaget HW, Ganesh S, Kubben FJ, Vahrmeijer AL, van de Velde CJ, Kuppen PJ, Quax PH, Sier CF, 2011. Clinical applications of the urokinase receptor (UPAR) for cancer patients. Curr Pharm Des 17: 1890-1910.

32. Solberg H, Romer J, BrünnerN, Holm A, Sidenius N, Danø K, Høyer-Hansen G, 1994. A cleaved form of the receptor for urokinase-type plasminogen activator in invasive transplanted human and murine tumours. Int J Cancer 58: 877-881.
33. Mustjoki S, Sidenius N, Sier CF, Blasi F, Elonen E, Alitalo R, Vaheri $A, 2000$. Soluble urokinase receptor levels correlate with number of circulating tumor cells in acute myeloid leukemia and decrease rapidly during chemotherapy. Cancer Res 60: $7126-7132$.

34. Riisbro R et al., 2002. Prognostic significance of soluble urokinase plasminogen activator receptor in serum and cytosol of tumor tissue from patients with primary breast cancer. Clin Cancer Res 8: 1132-1141.

35. Plebani M, Herzènyi L, Carraro $P$, De Paoli M, Roveroni G, Cardin R, Tulassay Z, Naccarato R, Farinati F, 1997. Urokinase-type plasminogen activator receptor in gastric cancer: tissue expression and prognostic role. Clin Exp Metastasis 15: 418-425.

36. Beyer BCM, Heiss MM, Simon EH, Gruetner KU, Babic R, Jauch $\mathrm{KW}$, Schildberg FW, Allgayer H, 2006. Urokinase system expression in gastric carcinoma. Prognostic impact in an independent patient series and first evidence of predictive value in preoperative biopsy and intestinal metaplasia specimens. Cancer 106: 1026-1035.

37. Fidan E, Mentese A, Ozdemir F, Deger O, Kavgaci H, Caner Karahan S, Aydin F, 2013. Diagnostic and prognostic significance of CA IX and suPAR in gastric cancer. Med Oncol 30: 540.

38. Kenny S, Duval C, Sammut SJ, Steele I, Pritchard DM, Atherton JC, Argent RH, Dimaline R, Dockray GJ, Varro A, 2008. Increased expression of the urokinase plasminogen activator system by Helicobacter pylori in gastric epithelial cells. Am J Physiol Gastrointest Liver Physiol 295: G431-G441.

39. Hu B, El Hajj N, Sittler S, Lammert N, Barnes R, Meloni-Ehrig A, 2012. Gastric cancer: classification, histology and application of molecular pathology. J Gastrointest Oncol 3: 251-261.

40. Lauren $P, 1965$. The two histological main types of gastric carcinoma: diffuse and so called intestinal-type carcinoma. An attempt at histo-clinical classification. Acta Pathol Microbiol Scand 64: 31-49.

41. Perez-Perez Gl, Dworkin BM, Chodos JE, 1988. Campylobacter pylori antibodies in humans. Ann Intern Med 109: 11-17.

42. Blaser MJ, Perez-Perez Gl, Kleanthous H, Cover TL, Peek RM, Chyou PH, Stemmermann GN, Nomura A, 1995. Infection with Helicobacter pylori strains possessing cagA is associated with an increased risk of developing adenocarcinoma of the stomach. Cancer Res 55: 2111-2115.

43. Quiñonez JM, Chew F, Torres O, Bégué RE, 1999. Nutritional status of Helicobacter pylori-infected children in Guatemala as compared with uninfected peers. Am J Trop Med Hyg 61: 395-398.

44. Dowsett SA, Archila L, Segreto VA, Gonzalez CR, Silva A, Vastola KA, Bartizek RD, Kowolik MJ, 1999. Helicobacter pylori infection in indigenous families of Central America: serostatus and oral and fingernail carriage. J Clin Microbio/ 37: 2456-2460.

45. Samloff IM, Stemmermann GN, Heilbrun LK, Nomura A, 1986. Elevated serum pepsinogen I and II levels differ as risk factors for duodenal ulcer and gastric ulcer. Gastroenterology 90: 570-576.

46. He CY, Sun LP, Gong YH, Xu Q, Dong NN, Yuan Y, 2011. Serum pepsinogen II: a neglected but useful biomarker to differentiate between diseased and normal stomachs. J Gastroenterol Hepatol 26: 1039-1046.

47. Wellmann IA, Villagrán $\mathrm{Cl}$, Fernández-Botrán $\mathrm{R}$, Hernández $\mathrm{E}$, Méndez-Chacón E, Une C, 2018. Valor diagnóstico de las proteínas UPAR en sangre para el cáncer gástrico en Guatemala. Ciencia Tecnología y Salud 5: 43-53.

48. Hildenbrand R, Leitz M, Magdolen V, Luther T, Albrecht S, Graeff $\mathrm{H}$, Stutte HJ, Bleyl U, Schmitt M, 2000. Validation of immunolocalization of the urokinase receptor expression in ductal carcinoma in situ of the breast: comparison with detection by non-isotopic in-situ hybridization. Histopathology 36: 499-504.

49. Pyke C, Ralfkiaer E, Ronne E, Høyer-Hansen G, Kirkeby L, Danø K, 1994. Immunohistochemical detection of the receptor for urokinase plasminogen activator in human colon cancer. Histopathology 24: 131-138. 